\title{
COMPARATIVE PARAMETRIC ANALYSIS OF GAS FLOW IN THREE DIFFERENT DESIGNS OF IN-LINE SCRUBBER BOTTOM INLET
}

\author{
Daniela-Elena Jugănaru, Ionuț Voicu, Mariana Panaitescu, \\ Viorel Panaitescu, Cătălin Faitar
}

\author{
Constanta Maritime University, Faculty of Electromechanics \\ 104 Mircea cel Batran Street, 900663 Constanta, Romania \\ Corresponding author: Cătălin Faitar, catalinfaitar@yahoo.ro
}

\begin{abstract}
In this study, gas flow fields were simulated using ANSYS 2020R2, Fluid Flow Fluent computational fluids dynamic (CFD) software based on the continuity, velocity, temperature, energy and $\mathrm{k}-\varepsilon$ turbulence. The overall objective of the study is to compare the velocity maps inside the wet scrubber system for three different In-Line scrubber bottom inlet designs. Also, the behavior of the temperature of the mixture inside the scrubber is studied according to the number of nozzles provided by each system from those proposed for study. The numerical simulation using CFD is an effective method to study the flow characteristics of a counter-flow wet scrubber system and the most efficient wet scrubber model is the one with several. The results show that the residuals have a very good job of converging at minimum flow contours and vectors at the inlet across the scrubbing chamber and outlet shows a distributed flow. The speed of water droplets sprayed by the nozzles during mixing with waste gas in the scrubber chamber is double at model with 52 nozzles compared to the first model, equipped with only 13 nozzles. The velocity of clean gases discharged to the ship's hull shows increases of over $100 \%$ of the values, with the increase of the number of nozzles. Spray nozzles improve mixing between the scrubbing liquid and waste gas, by injecting liquid through nozzles to create a fine droplet spray pattern. In this study it can be seen how the number of nozzles influences the quality of the mixture between the scrubbing liquid and waste gas.
\end{abstract}

Key words: In-line wet scrubber, CFD, nozzle, open-loop system.

\section{INTRODUCTION}

The development of the economy also led to the development of maritime transport. The global focus of emissions from marine diesel engines has increased significantly during the last couple of years. Today, there are about 50.000 merchant ships carrying $90 \%$ of international goods. The total tonnage of goods transported by sea worldwide increased from 9 billion tons in 2020 to 13 billion tons in 2020 and is expected to increase to 20 billion in 2025 [1].
Although shipping is indispensable for the world economy, it is estimated that the emissions generated by the ships will increase significantly by 2050 . Maritime transport, compared to other modes of transport, has the lowest rate of $\mathrm{CO}$ emissions, but in the case of greenhouse gas emissions it is estimated an increase of 150-200\% compared to the current level [1].

Among the ship's exhaust pollutants, sulphur oxides $\left(\mathrm{SO}_{\mathrm{x}}\right)$ are one of the main acid gases that cause atmospheric pollution.

HFO (Heavy Fuel Oil) used as ship fuel has a very high sulphur content, which varies between the global average of $27.000 \mathrm{ppm}$ and $10.000 \mathrm{ppm}$ in sulphur emission control areas [2, 3].

As of 1 January 2020, the IMO MARPOL Annex VI Regulation on limiting the sulfur content of fuel for ships to a maximum of $0.5 \%$ has entered into force (Figure 1). Regulation into IMO 2020 means increase freight transportation costs; uncertain by over monitoring, compliance and enforcement standards; lower environmental impact.

In order to comply with the new sulfur content limits according to IMO 2020, ship operators have same options,

- Switch to IMO - compliant fuels with lower sulfur content;

- Install scrubbers on ships to reduce sulphur oxide emissions;

- Use LNG or other alternative fuels.

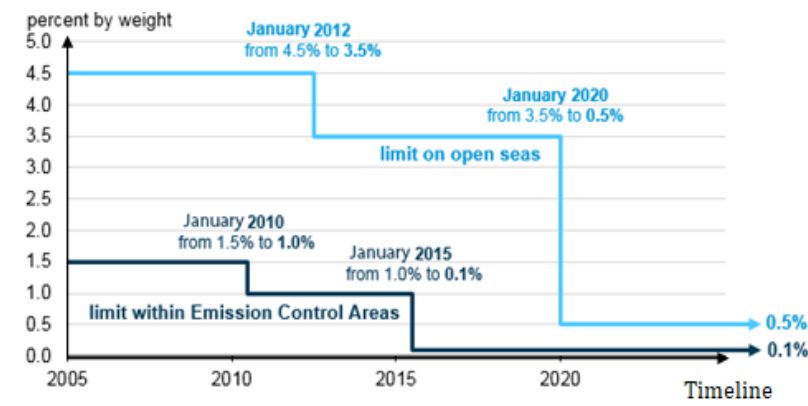

Fig. 1. Global marine fuel sulfur limits [4] 
Regulation 4'th of MARPOL Annex VI allows for Administrations (flag states) to approve "equivalents" - any "fitting, materials, appliance or apparatus to be fitted in a ship or other procedures, alternative fuel oils, or compliance methods used as an alternative to that required" [5] - that enables the same standards of emissions control to be met.

For reduction of sulphur oxide emissions, flag states have accepted and approved scrubbers - otherwise known as "Exhaust Gas Cleaning Systems" (EGCS) as meeting the requirements for sulphur oxide reduction [6].

The main objective of this paper lies in examining the flow characteristics and understanding of the processes in the De-SO $\mathrm{S}_{\mathrm{x}}$ scrubber to optimize the efficiency of the EGCS. These flow processes include the flue gas and droplet flows; agglomeration of droplets; flow of bulk water.

By using the Computational Fluids Dynamics (CFD) numerical analysis in ANSYS 2020R2, Fluid Flow Fluent, was simulated the gas flow fields in 3 different In-Line scrubber bottom inlet designs.

The CFD software is based on the continuity, velocity, energy, $\mathrm{k}-\varepsilon$ turbulence. The overall objective of the study is to compare the velocity maps inside the scrubber for these three models of In-Line scrubber bottom inlet designs. The differences between these three models are represented by the number of nozzles with which the exhaust gas scrubbing is equipped.

\section{THEORETICAL METHODS}

\subsection{Marine SO $\mathrm{S}_{\mathrm{x}}$ Scrubber}

The ship exhaust gas cleaning technology is available in three standard configurations, customizable to a ship's requirements,

- OPEN - LOOP: seawater is used to scrub the exhaust gas, after which it is legally discharged back into the sea (Figure 2);

- CLOSED - LOOP: fresh water is dosed with an alkaline additive and is recirculate after it becomes dirty;

- HYBRID: a combination of both designs for maximum flexibility.

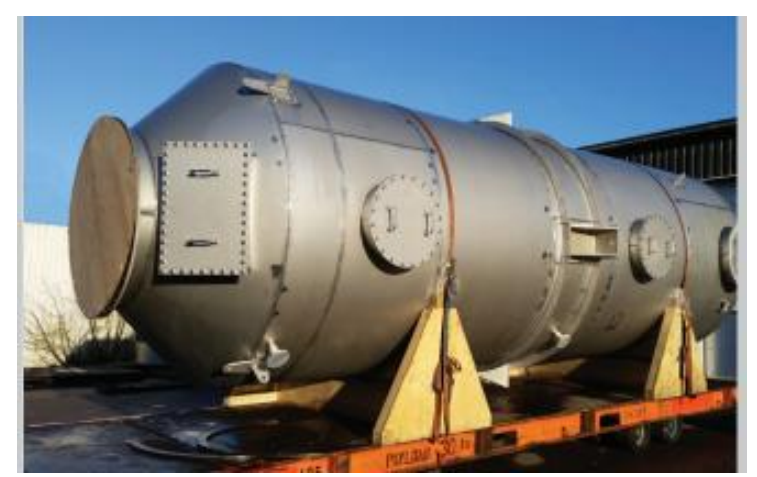

Fig. 2. OPEN - LOOP scrubber [7]
Figure 3 show the process inside the wet scrubber. During this process, water droplets are introduced at the top of an empty chamber through atomizing nozzles and fall freely at their terminal settling velocities counter-currently through the rising gas stream containing particles from industrial production. Then the particles are separated from the gas stream and collected in a pool at the bottom of the chamber. The cleaned gases existing in the scrubber passes through a mist pad which removed water droplets from the gas [8-14].

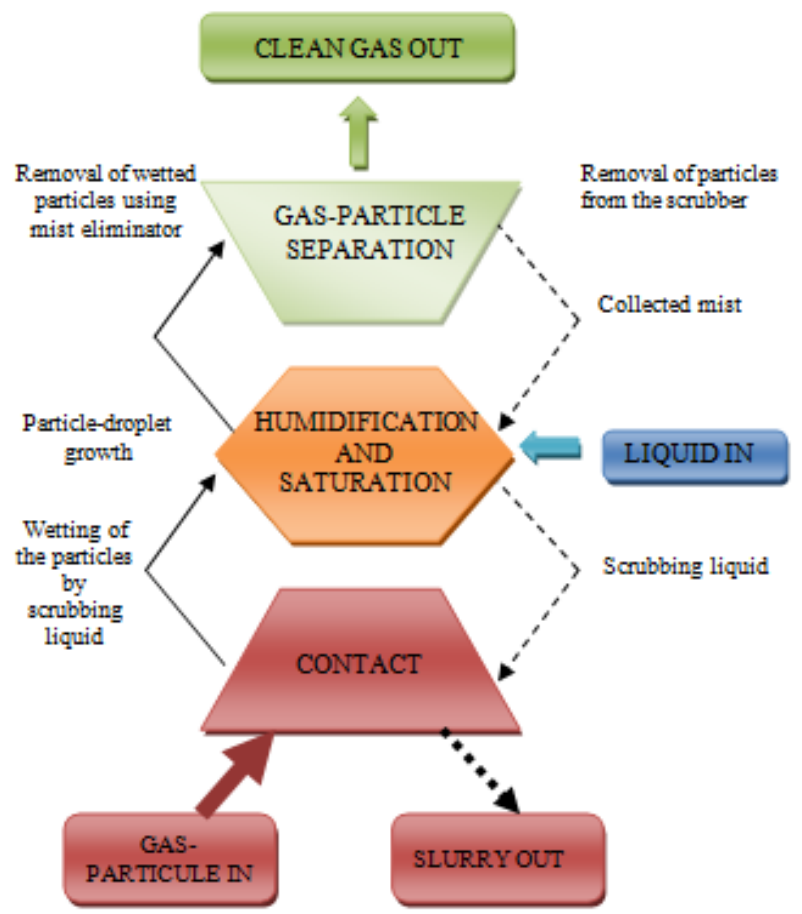

Fig. 3. Schematic diagram of wet scrubbing proces

Due to clogging, accumulation or erosion, simple scrubbers are used. Their configuration can be vertical or horizontal, and the flue gases can flow simultaneously or counter-currently by the liquid. The main disadvantage of spray towers is that they require a higher liquid-gas ratio for an equivalent $\mathrm{SO}_{2}$.

FGD (Fuel Gas Desulfurization) scrubbers produce a wastewater drain that needs treatment to comply with current regulations. However, technological processes in ion excenge membranes and electrolysis systems have allowed the high-efficiency treatment of FGD wastewater to meet recent EPA discharge limits.

\subsection{Factors influnecing scrubber system design} In principle, an EGC (exhaust gas cycle) scrubber system can be fitted on any type of ship sailing in any ocean in the word, but a great importance is given to the factors like sea water temperature, sea water alkalinity, fuel oil quality and engine or boiler type that influence on the dimensions and efficiency of the scrubber. There are three big categories of factors, like: external factors, vessel details and legislation. 
External factors are fuel oil type and quality, water quality, air temperature and relative humidity, and sea water temperature. The factors by the vessel details are: engine type and size; space restrictions and limitations on electrical power. Scrubbers are designed to comply with the guidelines as provided by MEPC under IMO, which are being implemented in EU, US and national legislation by taken into account the sulphur limit and discharge water [15].

\subsection{The chemistry of desulfurization}

Exhaust gas scrubbing desulfurization technology is currently a mature technology for controlling $\mathrm{SO}_{\mathrm{x}}$ emissions and had been widely used in power stations and industrial fields $[16,17]$.

Emission reduction technology works by spraying alkaline water into a vessel to remove sulphur and other unwanted chemicals, through an open loop system, a closed loop system or a hybrid system. The use of gas scrubbers will allow the eradication of almost half of ships' harmful emissions.

The liquid used to wash the flue gas is a water-based calcium solution. Limestone $\left(\mathrm{CaCO}_{3}\right)$ is cheap and creates an alkaline environment in water,

$$
\mathrm{CaCO}_{3}+\mathrm{H}_{2} \mathrm{O} \leftrightarrow \mathrm{Ca}^{++}+\mathrm{HCO}_{3}^{-}+\mathrm{OH}^{-}
$$

This $\mathrm{OH}^{-}$radicals bind with $\mathrm{SO}_{2}$ in solution to from a sulphur ion,

$$
\mathrm{SO}_{2}+\mathrm{OH}^{-} \leftrightarrow \mathrm{HSO}_{3}^{-}
$$

while water always dissociates a bit,

$$
\begin{gathered}
H_{2} O \leftrightarrow H^{+}+O H^{-} \text {(3) } \frac{\partial}{\partial t}(\rho \vec{u})+\nabla \cdot(\rho \vec{u} \vec{u})=-\nabla p+\nabla \cdot(\overline{\bar{\tau}})+\rho \vec{g}+\vec{F} \\
\frac{\partial}{\partial t}(\rho E)+\nabla \cdot(\vec{u}(\rho E+p))=\nabla \cdot\left(k_{e f f} \nabla T-h_{t} \vec{J}+\left(\overline{\bar{\tau}}_{e f f} \cdot \vec{u}\right)\right)+S_{h}
\end{gathered}
$$

The net result is the transformation of $\mathrm{CaCO}_{3}$ to calcium ions $\left(\mathrm{Ca}^{++}\right)$, the release of carbon dioxide and production of $\mathrm{HSO}_{3}^{-}$,

$$
\begin{aligned}
& \mathrm{CaCO}_{3}+2 \mathrm{SO}_{2}+\mathrm{H}_{2} \mathrm{O} \leftrightarrow \mathrm{Ca}^{++}+ \\
& \mathrm{CO}_{2}+2 \mathrm{HSO}_{3}^{-}
\end{aligned}
$$

The carbon dioxide bubbles up as a gas, while $\mathrm{HSO}_{3}^{-}$ remains in the water solution.

A natural alkaline that can be used to absorb $\mathrm{SO}_{2}$ is sea water. $\mathrm{CO}_{2}$ is absorbed into the water and when oxygen is added it reacts to $\mathrm{SO}_{4}^{2-}$ sulphate ions and free $\mathrm{H}^{+}$. The excess of $\mathrm{H}^{+}$is offset by carbonates in seawater that push the carbonate balance to release $\mathrm{CO}_{2}$ gas,

$$
\begin{gathered}
\mathrm{SO}_{2}+\mathrm{H}_{2} \mathrm{O}+\frac{1}{2} \mathrm{O}_{2} \rightarrow \mathrm{SO}_{4}^{2-}+2 \mathrm{H}^{+} \\
\mathrm{HCO}_{3}^{-}+\mathrm{H}^{+} \rightarrow \mathrm{H}_{2} \mathrm{O}+\mathrm{CO}_{2}
\end{gathered}
$$

\subsection{Governing Equations}

The mass, momentum, and energy conservation equation used in the CFD simulation are,

$$
\frac{\partial \rho}{\partial t}+\nabla \cdot(\rho \vec{u})=S_{m}
$$

where,

$S_{m}$-the source term of discrete phase acting on continuous phase;

$p$-static pressure $\left[\mathrm{N} / \mathrm{m}^{2}\right]$;

$\overline{\bar{\tau}}$-the stress tensor $\left[\mathrm{N} / \mathrm{m}^{2}\right]$;

$\rho \vec{g}$-the gravity force $\left[\mathrm{N} / \mathrm{kg}^{2} \mathrm{~m}^{2}\right]$;

$\vec{F}$-the external force [N];

$k_{\text {eff }}$-the actual heat transfer coefficient - the effect

of turbulence $\left[\mathrm{W} / \mathrm{m}^{2} \mathrm{~K}\right]$;

$\vec{J}$-the diffusion flux [mol/ms];

$S_{h}$ - the heat with chemical reaction [W].

$$
p V=m R T
$$

where,

$\mathrm{T}$-the gas temperature $[\mathrm{K}]$;

$\mathrm{m}$ - the mass $[\mathrm{kg}]$;

$\mathrm{V}$-the gas volume $\left[\mathrm{m}^{3}\right]$;

$\mathrm{R}-$ the gas constant $[\mathrm{J} / \mathrm{kmolK}] \quad(\mathrm{R}=$ $8.31451 \mathrm{~J} / \mathrm{kmolK}$ ).

Wet scrubber model use the standard $\mathrm{k}-\varepsilon$ turbulence model. The characteristic equations are,

$$
\rho \frac{D k}{D t}=\frac{\partial}{\partial x_{i}}\left[\left(\mu+\frac{\mu_{t}}{\sigma_{k}}\right) \frac{\partial k}{\partial x_{i}}\right]+G_{k}+G_{b} \rho \varepsilon-\mathrm{Y}_{M}, \mu_{t}=\rho C_{\mu} \frac{k^{2}}{\varepsilon}
$$




$$
\rho \frac{D \varepsilon}{D t}=\frac{\partial}{\partial x_{i}}\left[\left(\mu+\frac{\mu_{t}}{\sigma_{k}}\right) \frac{\partial \varepsilon}{\partial x_{i}}\right]+C_{1 \varepsilon} \frac{\varepsilon}{k}\left(G_{k}+C_{3 \varepsilon} G_{b}\right)-C_{2 \varepsilon} \rho \frac{\varepsilon^{2}}{\varepsilon}
$$

where,

$G_{k}$ - the turbulent flow energy due to the average

velocity gradient;

$G_{b}$ - the term of turbulent kinetic energy due to buoyancy;

$\rho$ - the density $\left[\mathrm{kg} / \mathrm{m}^{3}\right]$;

$\mathrm{Y}_{M}$ - the contribution of pulsating expansion in compressible turbulence;

$\mu_{t}$ - the turbulent viscosity $\left[\mathrm{kg} / \mathrm{m}^{3}\right]$;
$C_{1 \varepsilon}, C_{2 \varepsilon}, C_{3 \varepsilon}, C_{\mu}$ - constants [18].

\section{NUMERICAL ANALYSIS}

\subsection{CFD model description}

The 3D Computer Aided Design (CAD) structural geometry of the three models of scrubber chooses for analysis was shown in Figure 4. The dimensions of scrubber were shown in Table 1.

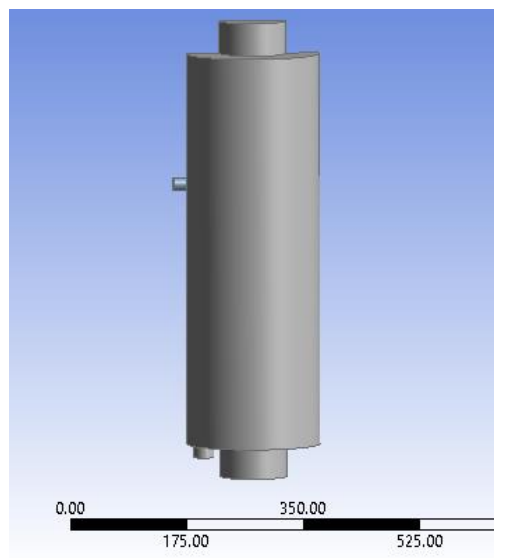

(a)

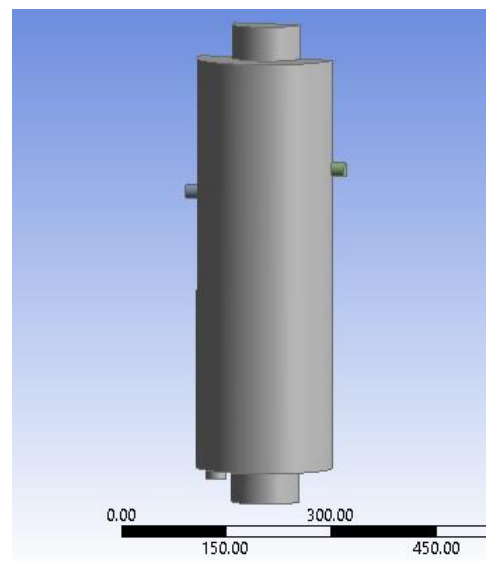

(b)

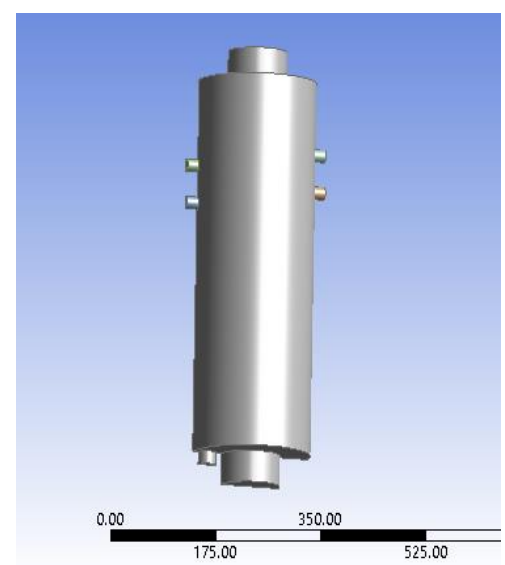

(c)

Fig. 4. The 3D models of wet scrubbers analysed: (a) 1 layer of nozzles;

(b) 2 layers of nozzles; (c) 4 layer of nozzles

During the simulation process, the scrubber model needs to be simplified to improve the quality of the mesh and optimize the simulation efficiency while ensuring the improvement of the calculation speed.

Table 1. Dimensions of analysed scrubber

\begin{tabular}{|c|c|}
\hline Part & Data $(\mathrm{cm})$ \\
\hline Scrubber height & 700 \\
\hline Scrubber diameter & 200 \\
\hline Waste gas inlet diameter & 100 \\
Clean gas outlet diameter & 100 \\
\hline Scrubbing liquid inlet diameter & 20 \\
Slurry outlet diameter & 30 \\
\hline
\end{tabular}

\subsection{Numerical modeling}

For simulated the gas flow field inside of a wet scrubber it was used the ANSYS 2020R2, Fluid Flow Fluent CFD software. This kind of analysis is based on the continuity, velocity, temperature, energy, k- $\varepsilon$ turbulence.

The overall objective of the study is to compare the velocity map inside the wet scrubber for three different In-Line scrubber bottom inlet designs. Also, the behaviour of the temperature of the mixture inside the scrubber is studied according to the number of nozzles provided by each installation from those proposed for study.

First model of the De-SO ${ }_{x}$ scrubber choose for analysis has one layer of nozzles inside with 13 nozzles. The second model has two layers of nozzles inside with 26 nozzles. And the third one has 4 layers of nozzles inside with 52 nozzles.

CFD codes that predict gas flow patterns are based on conservation equations for mass, momentum and energy. The mesh models are presented in Figure 5. After discretization, first model has 412983 computational meshes quad elements and 89789 nodes. Second model has 405523 quad elements and 87041 nodes and the last model has 407051 quad elements and 87862 nodes.





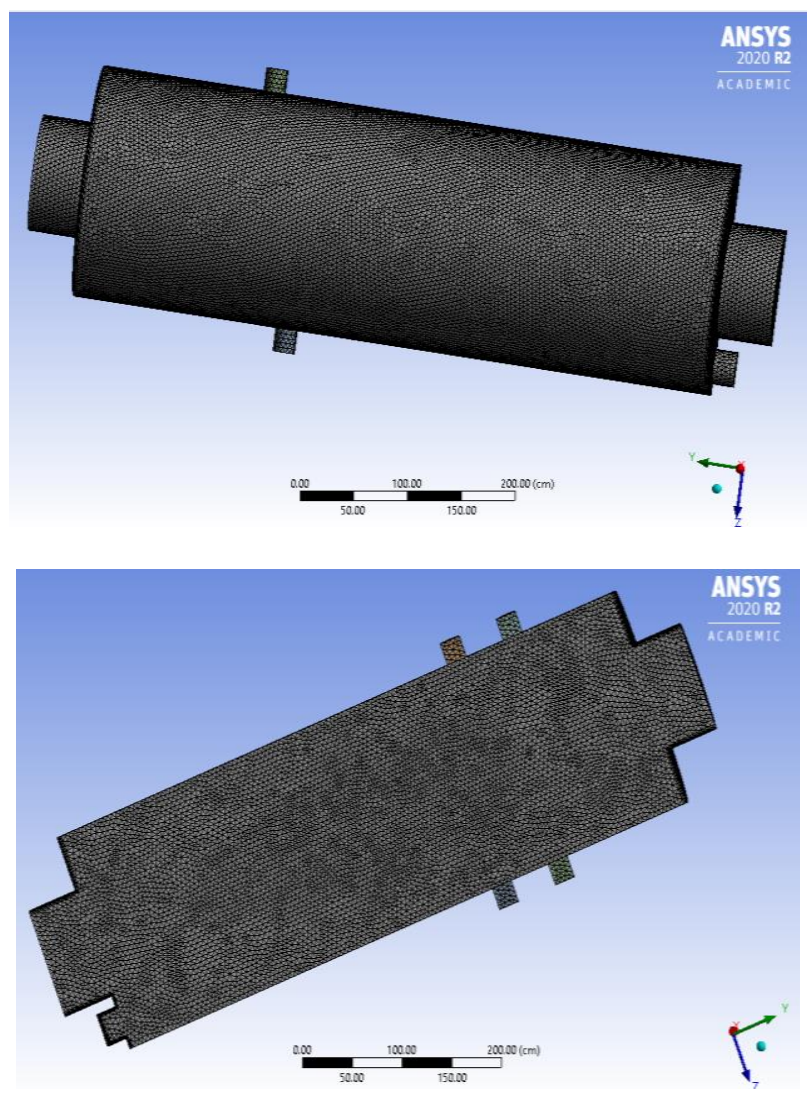

Fig. 5. Mesh Model

Each layer has 13 nozzles. The spray volume of the washing liquid is $120 \mathrm{~m}^{3} / \mathrm{h}$. The injection pressure of each nozzle is $0.2 \mathrm{MPa}$ and the spray cone angle is 90 . Table 2 shows the initial condition and Table 3 shows the CFD model boundary conditions.

Table 2. Initial conditions of analysis

\begin{tabular}{|l|c|}
\hline \multicolumn{1}{|c|}{ Parameters } & Data \\
\hline Temperature of the scrubber & $298 \mathrm{~K}$ \\
\hline Temperature of the wash water & $305 \mathrm{~K}$ \\
\hline Pressure of the scrubber & $101.324 \mathrm{~Pa}$ \\
\hline Flow rate of each nozzles & $77 \mathrm{l} / \mathrm{min}$ \\
\hline
\end{tabular}

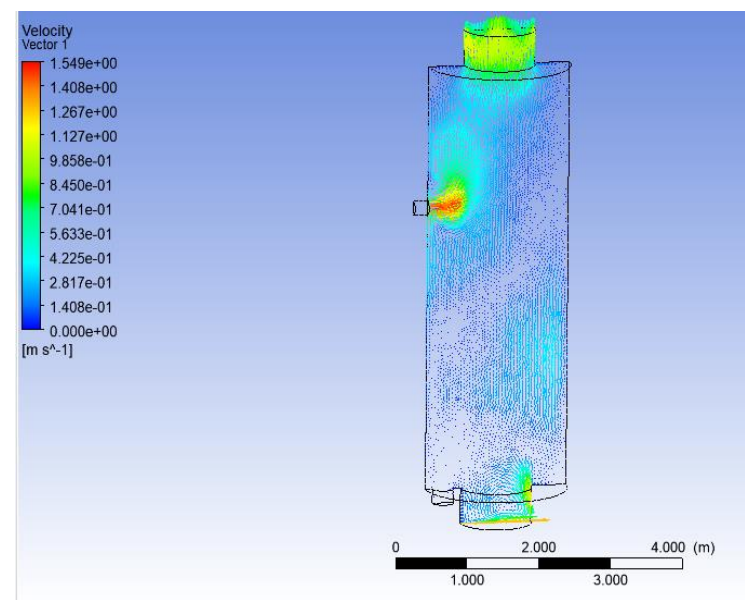

(a)

Table 3. CFD model boundary conditions

\begin{tabular}{|c|l|l|}
\hline Index & Boundary conditions & Data \\
\hline Inlet & Mass flow rate & $23.75 \mathrm{~kg} / \mathrm{s}$ \\
\hline Inlet & Gas temperature & $485 \mathrm{~K}$ \\
\hline Outlet & Gas pressure & $101.324 \mathrm{~Pa}$ \\
\hline
\end{tabular}

The pressure drop of the simulation is less than 1000 $\mathrm{Pa}$ and the gas velocity in the patching bed less than $3.5 \mathrm{~m} / \mathrm{s}$.

\section{RESULTS AND DISCUSSION}

The results of the analysis for the three models of the In-Line Scrubber Bottom Inlet shows that the maximum value of the velocity was $3.327 \mathrm{~m} / \mathrm{s}$ and this velocity correspond of scrubber with 4 layers of nozzles.

Table 4 show the results for all the scrubber models analysed.

Table 4. Values of velocity, pressure and turbulent kinetic energy obtained by numerical simulation

\begin{tabular}{|c|c|c|c|}
\hline Parameter & $\begin{array}{c}\text { Scrubber } \\
\text { with } 1 \\
\text { layer } \\
\text { (13 nozzles })\end{array}$ & $\begin{array}{l}\text { Scrubber with } \\
2 \text { layers } \\
\text { (26 nozzles) }\end{array}$ & $\begin{array}{c}\text { Scrubber with } \\
4 \text { layers } \\
\text { (52 nozzles) }\end{array}$ \\
\hline $\begin{array}{l}\text { Velocit } \\
\text { y (max } \\
\text { value) }\end{array}$ & $\begin{array}{l}1.549 \\
{[\mathrm{~m} / \mathrm{s}]}\end{array}$ & $2.179[\mathrm{~m} / \mathrm{s}]$ & $3.327[\mathrm{~m} / \mathrm{s}]$ \\
\hline $\begin{array}{l}\text { Pressur } \\
\mathrm{e}-\text { min } \\
-\max \end{array}$ & $\begin{array}{c}-182.036 \\
{[\mathrm{~Pa}]} \\
+251.564 \\
{[\mathrm{~Pa}]} \\
\end{array}$ & $\begin{array}{l}-203.691[\mathrm{~Pa}] \\
+203.83[\mathrm{~Pa}]\end{array}$ & $\begin{array}{l}-118.021[\mathrm{~Pa}] \\
+214.334[\mathrm{~Pa}]\end{array}$ \\
\hline $\begin{array}{l}\text { Turbule } \\
\text { nt } \\
\text { kinetic } \\
\text { energy - } \\
\text { min } \\
\text { - max }\end{array}$ & $\begin{array}{c}4.9735 \times 1 \\
0^{-8}\left[\mathrm{~m}^{2} / \mathrm{s}^{2}\right] \\
22.1060 \\
{\left[\mathrm{~m}^{2} / \mathrm{s}^{2}\right]}\end{array}$ & $\begin{array}{c}3.5818 \times 10^{-} \\
{ }^{7}\left[\mathrm{~m}^{2} / \mathrm{s}^{2}\right] \\
25.2411\left[\mathrm{~m}^{2} / \mathrm{s}^{2}\right]\end{array}$ & $\begin{array}{c}1.3010 \times 10^{-} \\
5\left[\mathrm{~m}^{2} / \mathrm{s}^{2}\right] \\
19.9552\left[\mathrm{~m}^{2} / \mathrm{s}^{2}\right]\end{array}$ \\
\hline
\end{tabular}

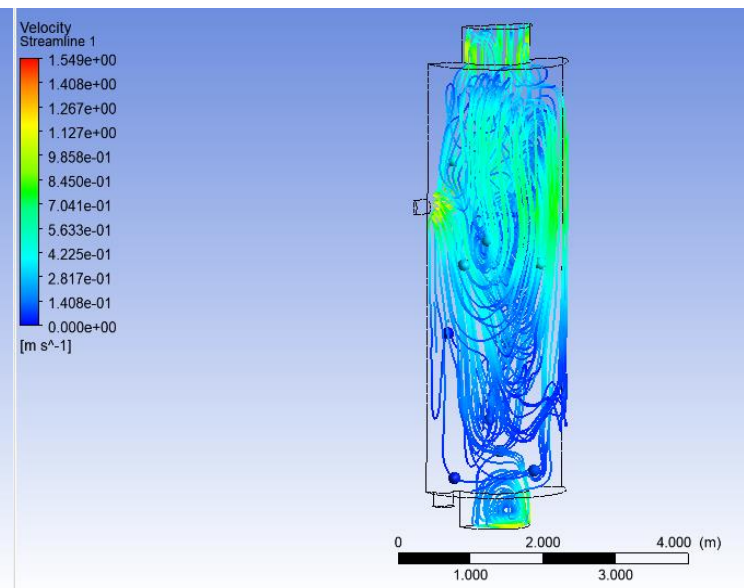



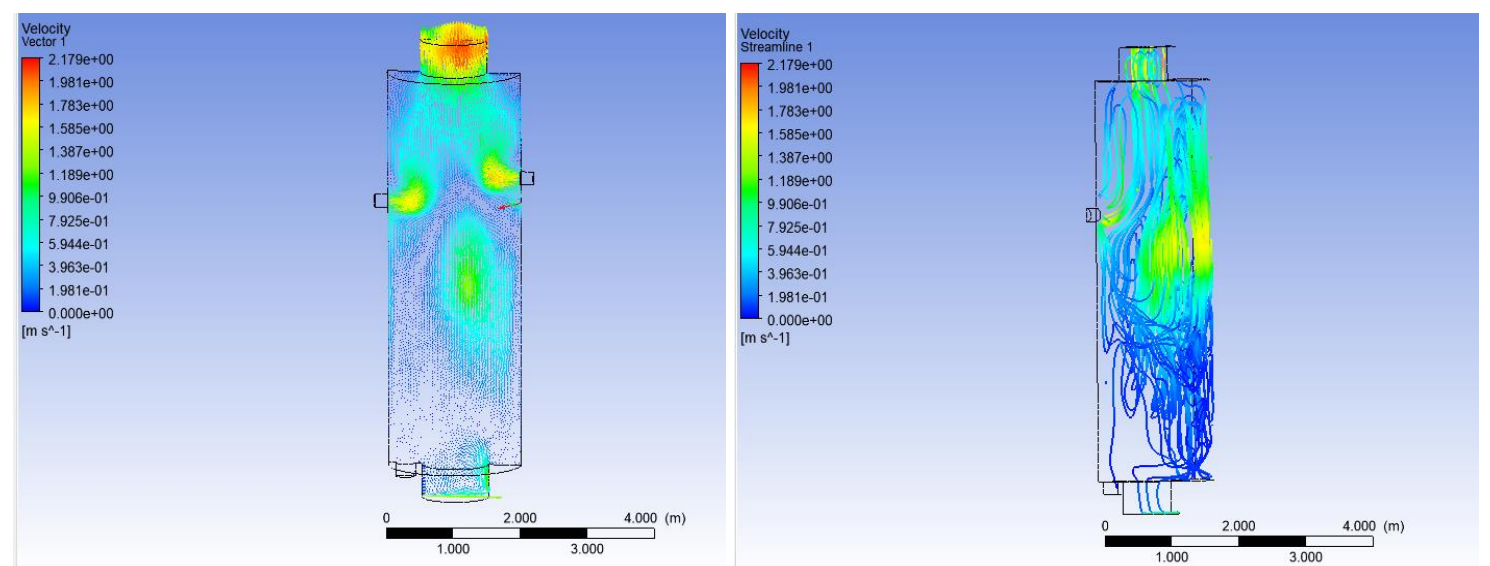

(b)

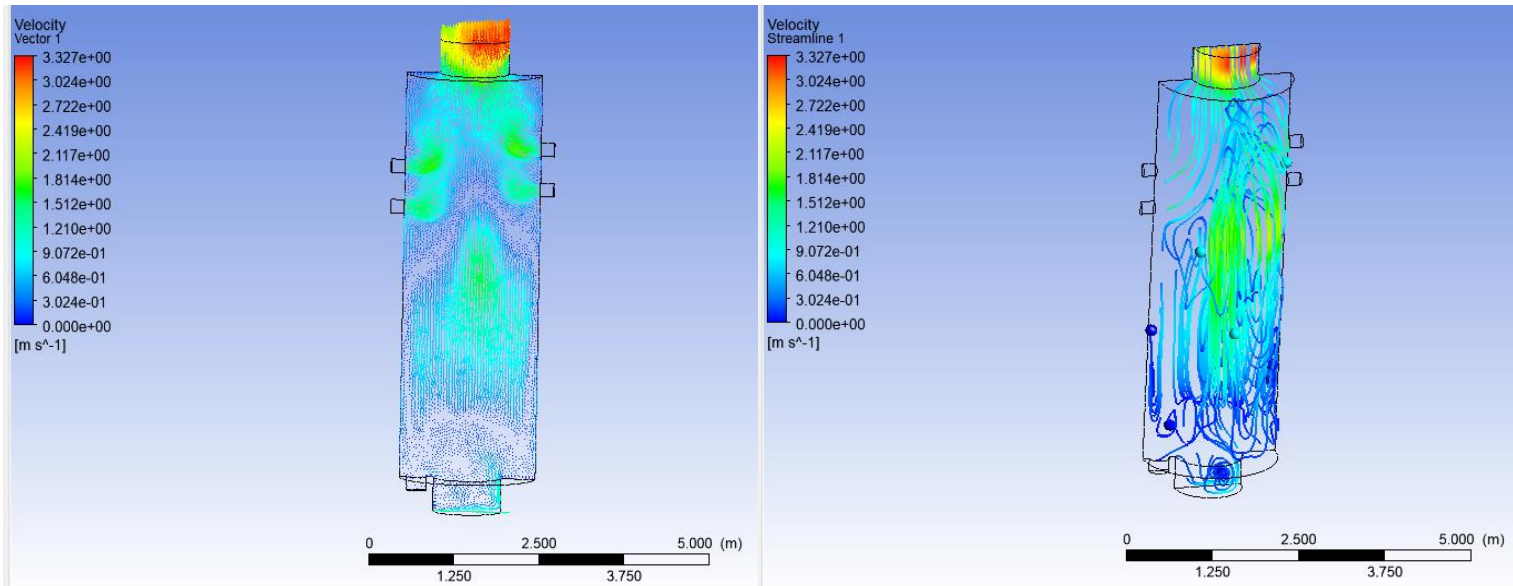

(c)

Fig. 6. Velocity vectors contour ant the 3D streamlines of the wet scrubber (a) model with 1 layer of nozzles; (b) model with 2 layers of nozzles;

(c) model with 3 layers of nozzles

Figure 6 shows the speed vectors contour and the 3D streamlines of the flow field inside the scrubber. Thus, we can see the flow velocity of the mixture inside the scrubber, the trajectory and the density of the flow using the velocity vector. In all three cases studied, it can be easily seen that the velocity reaches high values in the output section. The dirty gases coming from the combustion processes in the engine are humidified with a quantity of water sprayed by the scrubber nozzles. Following this process, the gases are washed, and the clean gases will then be removed to the ship's hull. Water droplets loaded with sulphur molecules and hydrocarbons will accumulate at the bottom of the scrubber, from where they will then be collected. The higher the amount of water sprayed by the nozzles for washing waste gases, the higher the speed of leaving the scrubber of clean gases. This situation can be seen in Figure 6(c). By doubling the number of nozzles (Figure 6 (b) and (c)), gas velocity increases by $50 \%$. Compared to the first model, this velocity increase is $115 \%$ (Figure 6(a) and (c)).



Fig. 7. Temperature field map

The temperature fields of the whole scrubber of all the models analysed at $\mathrm{t}=1 \mathrm{~s}$ are shown in Figure 7 . The high temperature exhaust gas enters the lower layer of the scrubber from the bottom side. Figure 7 shown the temperature map inside the scrubber after $1.0 \mathrm{~s}$ when the exhaust gas contacts the coting layer droplets and start to cool down. This is because the 
flue gases exhaust heat with the droplets during the ascending process.

\section{CONCLUSIONS}

The results show that the residuals have a very good job of converging at minimum flow contours and vectors at the inlet across the scrubbing chamber and outlet shows a distributed flow. The velocity profiles have fully conformed to the recommended profile for turbulent flow in pipes.

The temperatures map varies for the 3 models and the map with lower temperatures can be easily seen, as it corresponds to the model with 52 nozzles. The speed of water droplets sprayed by the nozzles during mixing with waste gas in the scrubber chamber is double at model with 52 nozzles compared to the first model, equipped with only 13 nozzles. Spray nozzles improve mixing between the scrubbing liquid and waste gas, by injecting liquid through nozzles to create a fine droplet spray pattern. In our case, the scrubbing liquid used in analyze was fresh water. From these results, it can be deducted that the numerical simulation using CFD is an effective method to study the flow characteristics of a counterflow wet scrubber system and the most efficient wet scrubber model is the one with several nozzles.

\section{REFERENCES}

1.https://ec.europa.eu/commission/presscorner/detail/r o/IP_10_1747 (access date: 01/23/2021).

2. Murphy S M, Agrawal H, Sorooshian A, Padró LT, Gates H, Hersey S, Welch W, Jung H and Miller J, (2009), Comprehensive simultaneous shipboard and airborne characterization of exhaust from a modern container ship at sea, Environ. Sci. Technol., 43, 4626-4640.

3. Wang GX and Yu WB, (2019), Experimental and numerical study on the influence of intake swirl on fuel spray and in-cylinder combustion characteristics on large bore diesel engine, Fuel, 237, 209-221.

4. U.S. Energy Information Administration, based on International Maritime Organization, https://www.eia.gov/todayinenergy/detail.php?id=377 93 (access date: 05/7/2021).

5. https://www.epa.gov/enforcement/marpol-annexvi-and-act-prevent-pollution-ships-apps (access date: 01/23/2021).

6.https://www.imo.org/en/MediaCentre/HotTopics/Pag es/Sulphur-2020.aspx (access date: 01/23/2021).

7. CROE Exhaust gas cleaning systems. The emissions solution https://www.croceanx.com/wpcontent/uploads/2015/06/CR_Ocean_Brochure_2019. pdf (access date: 01/22/2021).
8. Danzomo BA, Salami M-J E, Khan and Md R, (2012), Artificial Neural Network Model for Predicting Wet Scrubber, Performance International Journal of Scientific \& Engineering Research, 3(11) ISSN 2229-5518.

9. Makkinejad N., (2001), Temperature Profile in Counter current/concurrent Spray Towers, International Journal of Heat and Mass Transfer, 44 429-442.

10. Kim H T, Jung $\mathrm{C} \mathrm{H}$, Oh S N and Lee K W., (2011), Particle Removal Efficiency of Gravitational Wet Scrubber Considering Diffusion, Interception and Impaction, Journal of Environmental Engineering Science, 188(2).

11. Rahimi A, Taheri M and Fathikaljahi J., (2002), Mathematical Modelling of Heat and Mass Transfer in Hot Gas Spray Systems, Journal of Chemical Engineering Communications, 189, 959- 973.

12. Bingtao Z., (2005), Modelling of Particle Separation in Bends of Rectangular Cross section, American Journal of applied Sciences, 2(1), 394-396. 13. Garba M N, (2005), Gas Particle Separation Using Wet Scrubber Method M.Eng Thesis Submitted To The Department of Mechanical Engineering, Bayero University Kano Nigeria.

14. Bozorgi Y, Keshvarz P, Taheri $\mathrm{M}$ and Fathikaljahi J., (2006), Simulation of a Spray Scrubber Performance with Eulerian/Lagrangian Approach in the Aerosol Removing Process, Journal of Hazardous Material, B137, 509-517 (www.elsevier.com/locate.jhazmat).

15. Hasen JP, Kaltoft J et al. (2014), Reduction of SO2, NOX and particulate matter from ships with diesel engines Environmental Project no 1510.

16. Carotenuto C, Di Natale Fand Lancia A., (2010), Wet electrostatic scrubbers for the abatement of submicronic particulate, Chem. Eng. J., 165, 35-45.

17. Di Natale F, Carotenuto $\mathrm{C}$ and D'Addio L, (2013), New technologies for marine diesel engine emission control, Chem. Eng. Trans, 32, 361-366.

18. Guo H, Zhou S, Shreka M and Feng Y., (2020), A Numerical Invertigation on the Optimization of Uneven Flow in a Marine De-SO $O_{x}$ Scrubber College of Power and energy Engineering Harbin Engineering University Harbin China.

Received: March 04, 2021 / Accepted: December 20, 2021 / Paper available online: December 25, 2021 (C) International Journal of Modern Manufacturing Technologies 